\title{
A Case Of Harlequin Fetus With Psoriasis In His Family
}

\section{Gurses, I Kilic, M Baskan}

\section{Citation}

D Gurses, I Kilic, M Baskan. A Case Of Harlequin Fetus With Psoriasis In His Family. The Internet Journal of Dermatology. 2000 Volume 1 Number 1.

DOI: $\underline{10.5580 / 5 \mathrm{c} 6}$

\section{Abstract}

Harlequin fetus is the most severe form of congenital ichthyosis with an incidence of one in 300.000 births. An autosomal recessive pattern of inheritance is seen in this disorder. However; a new autosomal dominant mutation may possibly be responsible. The disorder has an ominous prognosis since the neonates usually die in the first hours or days of life. We reported here; a case of harlequin fetus with a history of psoriasis in his father.

\section{INTRODUCTION}

Harlequin fetus is the most severe form of congenital ichthyosis $\left({ }_{1}\right)$. The earliest record of its description is from the Oliver Hart in $\left.1750 \mathrm{(}_{2}\right)$. Since then it has been referred to as "fetal ichthyosis", "ichthyosis intrauterina", "keratosis diffusa fetalis", "congenital diffuse maligna keratoma", "malignant keratosis", "alligator baby" $\left.{ }_{3}\right)$.

The disorder has an ominous prognosis, and affected babies usually die within the first days to weeks of life $(1,4)$. The disorder is being presented here because of its extreme rarity and a history of psoriasis in his father.

\section{CASE REPORT}

An hour-old male infant was referred to Pamukkale University Hospital. He was born at 35-36 weeks gestation to a gravida I para 0 , following a normal pregnancy. The parents were not relatives. The mother was 21 years old and the father was 23 years old. His father had psoriasis diagnosed a year ago.

Physical examination revealed an infant weighing $1700 \mathrm{~g}$. The patient's temperature was $35(\mathrm{C}$, pulse rate $110 / \mathrm{min}$, and respiratory rate $40 / \mathrm{min}$. The clinical appearance of the baby was striking. The skin was hard, thickened, waxy and yellowish in colour. It was split irregularly to reveal erythematous moist fissures. The ears were underdeveloped and rudimentary. There was severe ectropion and eclabium. The baby's cry was normal, but he was unable to suck effectively. The nose was deformed and flattened. The nostrils were only being visible after the skin removed.
There was not chonal atresia. Hairs were underdeveloped (Fig. 1). 


\section{Figure 1}

Figure 1: The patient showing ectropion, eclabium and thickened skin with deep fissures

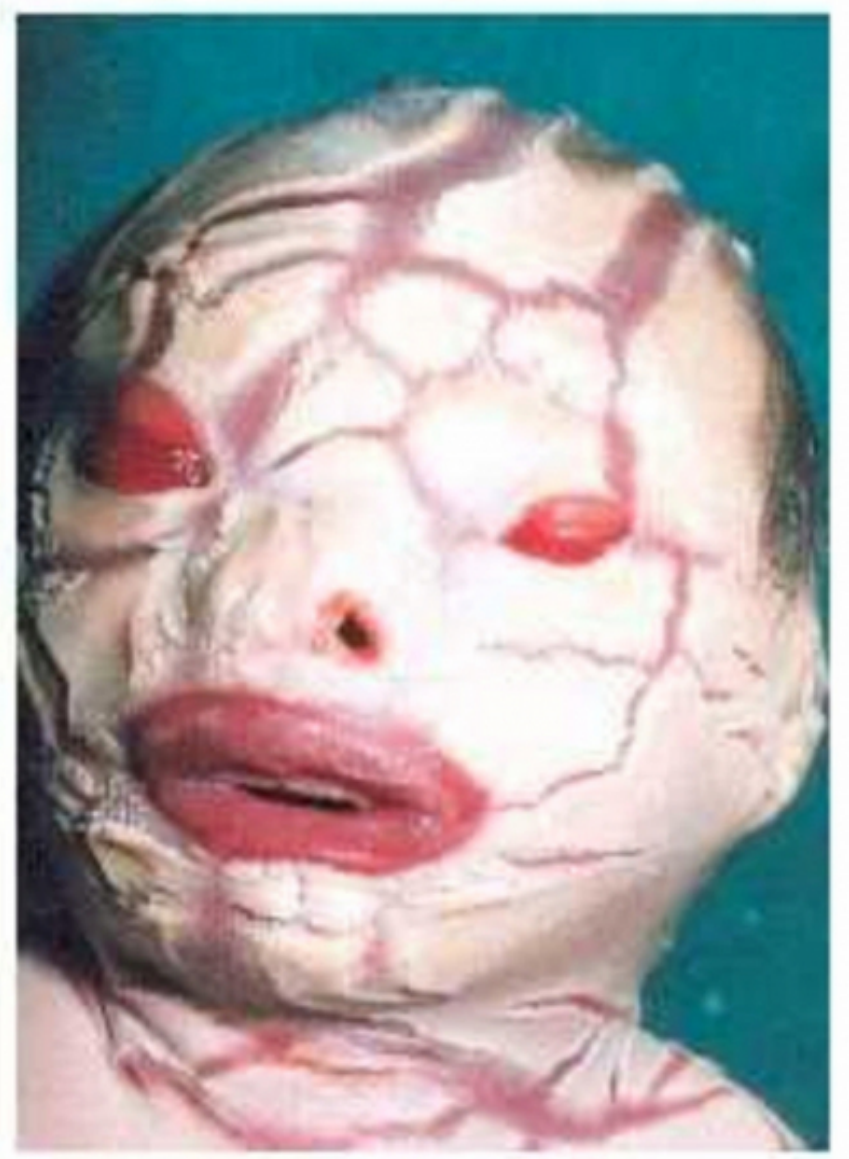

There was a small penis, undescended testes, and a rudimentary scrotum. The limbs were in a semiflexed position and had limited mobility (Fig. 2).

\section{Figure 2}

Figure 2: The patient with small testes and rudimentary scrotum

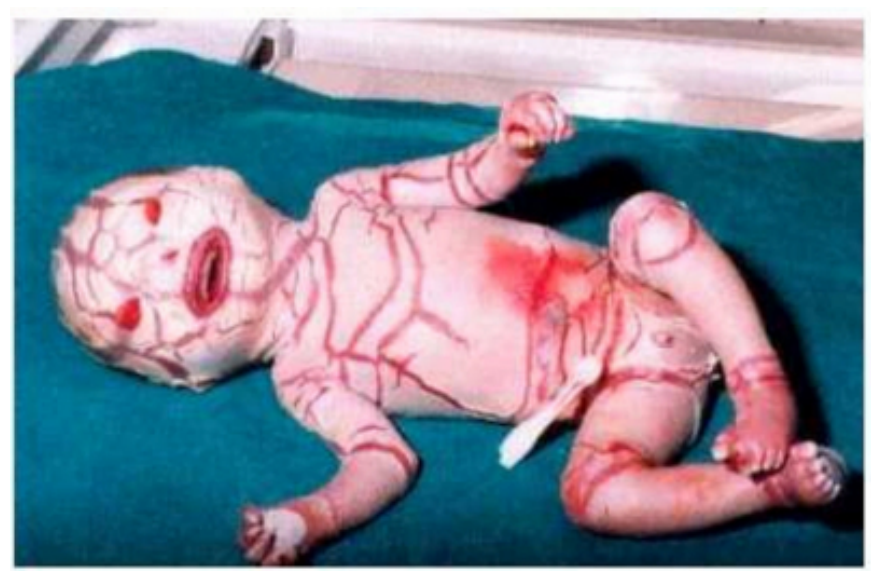

He had 60( flexion contractures at elbows and knees and no limitation in the movement at the wrist. Restricted abduction in the hip joint. The hands and feet were edematous with claw-like fingers and toes were clenched in a flexed position. The fingers and toes were hypoplastic and ischemic. The nails were absent (Fig. 3). The rest of the physical findings were unremarkable.

\section{Figure 3}

Figure 3: Edematous hands and clenched in a flexed position

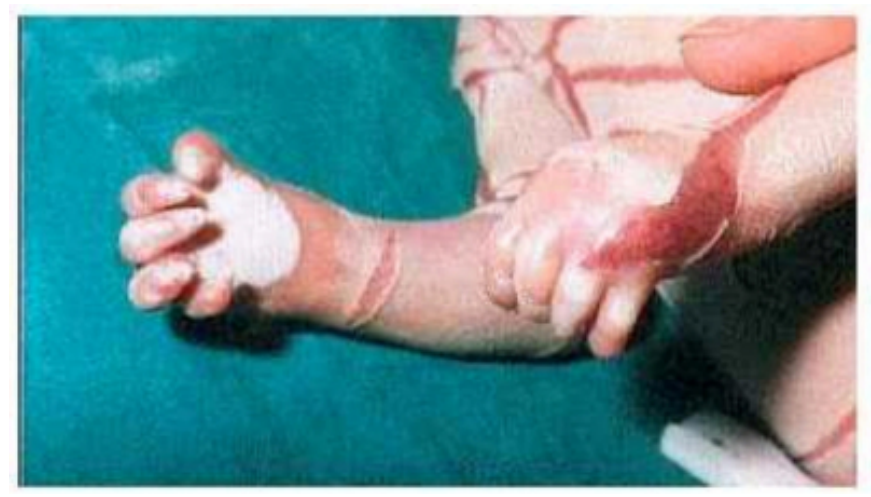

Laboratory findings included hemoglobin $15.1 \mathrm{~g} / \mathrm{dl}$, white blood cell count 10700/mm3, platelet count 192000/mm3, creatinin $0.6 \mathrm{mg} / \mathrm{dl}, \mathrm{Na} 128 \mathrm{mEq} / \mathrm{L}, \mathrm{K} 3.1 \mathrm{mEq} / \mathrm{L}, \mathrm{Cl} 101$ $\mathrm{mEq} / \mathrm{L}$, AST $9 \mathrm{U} / \mathrm{L}$, ALT $12 \mathrm{U} / \mathrm{L}$.

Immediately after transfer to our neonatal intensive care unit, the baby was nursed in a humidified incubator maintained at 33(C. As peripheral venous access was difficult, an umbilical venous line was set up. An extra 25\% allowance was provided for fluid and calorie requirements from the first day. After taking appropriate cultures, antibiotics were commenced in order to prevent infection. Vaseline containing five percent lactic acid and local antiseptics were applied topically. Ectropion was covered with eye pads soaked in saline.

Initially progress was slow. The plate like scales split and peeled off revealing glazed and erythematous skin underneath. There were necrotic areas on the tips of the fingers. He did not tolerate oral or N/G feeding and parenteral route for nutrition was used. His temperature was 38(C on the 16th day of admission. He was investigated for possible sites of sepsis. Twenty-one days after admission he had a cardiorespiratory arrest. A post-mortem examination could not be conducted. No micro-organisms grew in the cultures.

\section{DISCUSSION}

Harlequin fetus is a rare disorder with an incidence of 1 in 300.000 births ${ }_{5}$ ). The first report is from the diary of Oliver 
Hart, of Charleston, South Carolina who described these features in 1750 (2). These children are at great risk during the neonatal period and often die shortly after birth from the undernourishment caused by the rigidity of the lips, and underventilation and pneumonia because of respiratory distress. Abnormal water loss through the skin and poor temperature regulation lead to risk for infection beginning in the skin, but at the same time, because of poor temperature regulation, do not show the usual signs of infection. The taut skin may restrict normal respiration $(4,6)$. However the longest survial period reported was up to 2.5 years in a child who was treated with etretinate $\left(_{7}\right)$.

This disorder is reported from different ethnic groups and occurs in both sexes. There have been reports of several families with siblings affected with harlequin ichthyosis $\left(1,{ }_{8}\right)$. Twins affected by harlequin ichthyosis have also been reported (8). Occurrence of consanguinity in same parents and of harlequin ichthyosis in siblings suggest an autosomal recessive pattern of inheritance of this disorder (8).

However, consanguinity has not been observed in a large number of cases which makes it difficult to explain as an autosomal recessive mode of inheritance ${ }_{9}$ ). A new dominant mutation may possibly be responsible for the disorder $\left(9,{ }_{10}\right)$. There were not any consanguinity and sibling in our case.

Ultrastructural studies of this condition indicate that harlequin ichthyosis is a genetically heterogeneous group of disorders, with altered lamellar granules and intercellular lipids, and variations in expression and/or processing of structural protein markers of normal epidermal keratinization $\left(10,{ }_{11}\right)$. Dale and Kam (9) classified harlequin ichthyosis into three different types based on their epidermal protein analysis. They suggested a possible genetic defect altering the terminal differention based on their observation of the lack of desquamation and retention of cornified cells in the skin. Keratohyalin granules look fairly normal in type 1, are too small to be seen by light microscopy in type 2 , and are absent in type 3. In all types there are no lamellar granules; instead, there are small vesicles that lack internal structure. There is also no evidence of the lipid lamellar that from between granular and cornified cells as a result of discharge of lamellar granular contents into the intercellular space (6).

Ultrasonography and the electron microscopic examination of the fetal skin biopsy permit the possibility of prenatal diagnosis of this disorder $(1,3,9)$.

Oral vitamin A, topical antiseptics, liquid paraffin, five percent lactic acid lotions have been used and found effective in the treatment of congenital ichthyosis $\left(_{12}\right)$. Erdem (12) has reported five collodion babies treated successfully with a topical vasoline preparation which contained five percent lactic acid. Etretinate is a synthetic retinoid derived from vitamin A. Its mode of action is unknown but retinoids have been shown to control differentiation and proliferation of keratinising and non-keratinising epithelia $\left({ }_{13}\right)$. We could not find etretinate instead we used topical vasoline preparation which contained five percent lactic acid.

The development of digital gangrene, as occurred in our patient in second day, has been reported previously $\left({ }_{14}\right)$.

In this case; interestingly his father had psoriasis. The lesions of psoriasis is characterized by erythematous papules that coalesce to form plaques with sharply demarcated, irregular borders. The pathogenesis is also unknown: epidermal turnover time, however, is distinctly accelerated compared with that normal epidermis. The mode of transmission is unknown; a multifactorial type of inheritance has been proposed. There is an association with histocompatibility antigens (HLA)-BW17, -B13, -B16 and -BW37 $\left.{ }_{15}\right)$.

Two unrelated boys were described in the literature who were born as collodion babies and subsequently developed non-bullous ichthyosiform erythroderma and flares of generalized sterile pustulosis, similar to generalized pustular psoriasis $\left({ }_{16}\right)$.

There is no report for the relation of harlequin ichthyosis and psoriasis. However both of them are inherited keratinization disorders. We would like to point out that there could be a relation between harlequin fetus and psoriasis.

\section{References}

1. Multani AS, Sheth FJ, Shah VC, Chinoy NJ, Pathak S.

Three siblings with Harlequin Ichthyosis in an Indian family. Early Human Dev 1996;19:229-323.

2. Waring JJ. Early mention of a Harlequin fetus in America. Am J Dis Child 1932;43:442.

3. Prasad RS, Pejaver RK, Hassan A, Dusari S, Wooldridge MA. Management and follow-up of Harlequin siblings. Br J Dermatol 1994;130:650-653.

4. Darrmstadt GL. Disorders of keratinization. In: Behrman RE, Kliegman RM, Arvin AM, Nelson WE, (eds). Textbook of Pediatrics (15th ed). Philadelphia: WB Saunders

Company, 1996;1869-1873.

5. Rook A, Wilkinson D, Ebling F. Textbook of

Dermatology. Blacwell: Oxford University press, 1972;1027-1039.

6. DiGiavanna J. Ichthyosiform Dermatoses. In: Freedberg IM, Eisen A, Wolff K, Austen KF, Goldsmith LA, Katz SI, Fitzpatrick TB, (eds). Dermatology in general medicine (5th 
ed). Mc Graw-Hill, 1999;593-594.

7. Lawlor F. Progress of Harlequin fetus to nonbullous ichthyosiform erythroderma. Pediatrics 1988;82:870-873.

8. Unamuno P, Pierola JM, Fernandez E, Roman C, Velasco

JA. Harlequin Fetus in four siblings. Br J Dermatol

1987;116:569-572.

9. Dale BA, Kam E. Harlequin Ichthyosis, variability in expression and hypothesis for disease mechanism. Arch Dermatol 1993;129:1471-1477.

10. Suzimori K, Kanzaki T. Prenatal diagnosis of Harlequin Ichthyosis by fetal skin biopsy: Report of two cases. Prenatal Diagn 1991;141:451-457.

11. Baden HP, Kubilus J, Rosenbaum K, Fletcher A. Keratinization in the harlequin fetus Arch Dermatol 1982;118:14-18.
12. Erdem G. Treatment of collodion babies with a topical preparation containing lactic acid. Turk J Pediatr 1982;24:97-101.

13. Ward PS, Jones RD. Successfull treatment of a Harlequin fetus. Arch Dis Child 1989;64:1309-1311. 14. Kouskoukis C, Minas A, Tousimis D. Ichthyosis congenita fetalis (harlequin fetus) Int J Dermatol 1982;21:347-348.

15. Darrmstadt GL, Lane A. Diseases of the Epidermis. In: Behrman RE, Kliegman RM, Arvin AM, Nelson WE, (eds).

Textbook of Pediatrics (15th ed). Philadelphia: WB Saunders Company, 1996;1863-1869.

16. Langtry JA, Carr MM, Ive FA, Gordon P, Hunter JA, Harper JI. Ichtyosiform erythroderma associated with generalized pustulosis. Br J Dermatol 1998;138:502-503. 


\section{Author Information}

Dolunay Gurses, MD

Clinical Instructor in Pediatrics, Pediatrics, Faculty of Medicine, Pamukkale University

\section{Ilknur Kilic, MD}

Associate Professor, Pediatrics, Neonatalogy, Faculty of Medicine, Pamukkale University

\section{Merve Baskan, MD}

Pediatrics, Faculty of Medicine, Pamukkale University 